\title{
COVID-19 and male reproductive system: pathogenic features and possible mechanisms
}

\author{
Arash Ardestani Zadeh ${ }^{1,2} \cdot$ Davood Arab ${ }^{1,2}$ \\ Received: 10 October 2020 / Accepted: 28 June 2021 / Published online: 7 July 2021 \\ (c) The Author(s), under exclusive licence to Springer Nature B.V. 2021
}

\begin{abstract}
Multiorgan dysfunction is the main characteristic of severe COVID-19 patients and the involvement of male reproductive system may occur among these patients. Although there is a limited evidence to confirm the orchitis and virus presence in the semen of patients, there are concerns about the transmission of virus through the semen. In addition, reduced fertility or infertility can be seen as consequences of severe COVID-19 in recovered subjects. In this study, we aimed to review articles related to COVID-19 and male reproductive system to find the possible underlying mechanisms of SARS-CoV-2 in affecting male fertility. The following keywords of SARS-CoV-2, COVID-19, testis, orchitis, semen, angiotensin-converting enzyme 2 (ACE2), hypothalamic-pituitary-testicular (HPT) axis, Hypothalamus, etc., were defined to find the related publications from standard search engines, e.g., PUBMED, SCOPUS, Google Scholar. According to studies, COVID-19 occurs in severe patients as respiratory disease, along with multi-organ failure. The most important mechanisms are classified as direct and indirect pathogenesis of SARS-CoV-2. The presence of ACE2 on the cell surface of various cells in testis increases the risk of direct infection by this virus. SARS-CoV-2 also affects the testis through the cytokine storm. In addition, the important role of HPT axis dysregulation through impaired Leydig cells and hypothalamus should be considered. Using antiviral and immunomodulatory therapy can be harmful for testis function. Further investigations are required to investigate potential mechanisms of male infertility in survivals of COVID-19. Since involvement of testis is essential for fertility, increasing the knowledge of health system may improve the outcomes.
\end{abstract}

Keywords Coronavirus disease 2019 - Orchitis · Angiotensin-converting enzyme 2 - Cytokine storm · Hypothalamicpituitary-testicular axis

\section{Introduction}

Coronaviruses (CoVs) are common cause of human respiratory diseases with a range of mild to severe symptoms (Kang et al. 2020). COVID-19 has led to a "public health emergency of international concern" (PHEIC) (Mohamed Khosroshahi et al. 2021). In December 2019, the outbreak of a novel virus, severe acute respiratory syndrome CoV-2 (SARS-CoV-2) from China led to a more recent coronavirus disease 2019 (Covid-19) pandemic (Yang et al. 2020b). Over the past decades, some viral respiratory infections, such as

Davood Arab

drdavoodarab@semums.ac.ir

1 Clinical Research Development Center, Kowsar Hospital, Semnan University of Medical Sciences, Semnan, Iran

2 Department of Surgery, Kowsar Hospital, Semnan University of Medical Sciences, Semnan, Iran
SARS- CoV (China in 2003), H1N1 influenza virus (Mexico in 2009) (Dawood et al. 2009), and Middle East respiratory syndrome CoV (MERS-CoV) (Saudi Arabia in 2012), were responsible for the global viral outbreak (Matoba et al. 2015; Shirato et al. 2014). SARS-COV-2 is a human CoV that belongs to the Coronaviridae family with a non-segmented large positive-sense, single-stranded RNA genome (Cabeça et al. 2013; Li et al. 2020a). The genomic characteristics of SARS-COV-2 is a bat-origin CoV. Its sequences is 79.5\% similar to SARS-CoV (Andersen et al. 2020). The structural proteins, including spike (S) glycoprotein, matrix (M), envelope $(\mathrm{E})$, and nucleocapsid $(\mathrm{N})$ proteins, are translated from this genome (Guo et al. 2020). SARS-CoV-2 directly infects the host cells by using similar receptor of SARS$\mathrm{CoV}$ and leads to similar pathophysiological characteristics (Prompetchara et al. 2020). SARS-CoV-2 may bind to cells angiotensin-converting enzyme 2 (ACE2) receptor, a monocarboxypeptidase on the host cell, though spike-protein 
(Hoffmann et al. 2020). Then, the activated transmembrane protease serine 2 (TMPRSS2) facilitates the entry and spread of the virus through interfacing with the ACE2 receptor in the host cell (Huang et al. 2020; Lu et al. 2020). ACE2 is a member of renin-angiotensin-aldosterone system (RAAS) family, which involves in the regulation of blood pressure. While this receptor is highly spread in the respiratory system (He et al. 2006), its presence in other organs such as the heart, liver, and kidney has been reported (RocaHo et al. 2017). Since the high concentration of ACE2 has been found in the respiratory system, respiratory disease is the most common characteristic of COVID-19 (Zhang et al. 2020a). Different cell types of respiratory system express ACE2, including alveolar epithelial type II cells, bronchiolar epithelial cells, and lung vascular cells (endothelium and arterial smooth muscle cells) (Shenoy et al. 2011; Zhang et al. 2020a). However, the involvement of other organs was reported in critically ill patients (Wang et al. 2020). It seems that the distribution of this receptor in other organs may be responsible for the non-respiratory manifestation of COVID-19 patients, e.g., cardiac diseases (myocardial injury, arrhythmia) and acute kidney injury (Hamming et al. 2004; Leng et al. 2020). The expression of the ACE2 receptor on other cells such as myocardial cells, epithelial cells of the esophagus, and epithelial cells of the ileum has been confirmed by single-cell RNA sequencing (Zou et al. 2020). SARS-CoV-2 is more contagious than other $\mathrm{CoVs}$, including SARS-CoV and MERS-CoV. This virus can be transmitted human-to-human through direct contact, droplets, or stool. Because of asymptomatic cases and/or incubation period of 1-14 days (commonly 3-7 days) in infected patients, the risk of silent spreading is higher than other viruses (Naicker et al. 2020).

The most common manifestations of COVID-19 are fever and dry cough, and difficulty breathing, dyspnea, and fatigue have been reported (Adhikari et al. 2020; McMichael 2020). The illness progresses as severe form with dyspnea, hypoxemia, and acute respiratory distress syndrome (ARDS) within 1 week following the onset of disease (Chen et al. 2020). The mortality rate of COVID-19 seems to be related to ARDS, followed by multi-organ impairment (hepatic, renal, cardiac, and gastrointestinal complications), resulting in death (El Zowalaty and Järhult 2020; Shanmugaraj et al. 2020; Zhou et al. 2020). Moreover, the underlying diseases such as kidney, liver, and cardiovascular disease, malignant tumors, and old age (older than 50) are risk factors to worsen the prognosis of illness (Chen et al. 2020; Cui et al. 2020). The other problem is associated with the reproductive system involvement, which may enhance the risk of fertility issues in infected patients (Ma et al. 2020). Thus, the potential multiorgan impairment needs to be considered in clinical approaches to prevent and treat COVID-19 patients (Chen et al. 2020). While there is a possibility of infertility in male patients, there is limited information on management of these patients.

In this review, we aimed to investigate the possibility of infertility or reduced fertility in COVID-19 patients and discover potential underlying pathogenic mechanisms of infertility induced by SARS-CoV-2.

\section{Male reproductive system in COVID-19 patients}

It has been recorded that men are more susceptible to infection with SARS-CoV-2 than women (Jin et al. 2020). Exposure to SARS-CoV-2 can lead to infertility in male patients and survivors due to some potential alterations, such as hypothalamic and pituitary dysfunction, disrupted sex hormone profile, and testicular atrophy (Selvaraj et al. 2021). In a study, scrotal discomfort was observed in $19 \%$ of patients during the diagnosis for COVID-19 (Pan et al. 2020). Moreover, a case of COVID-19 with severe bilateral testicular pain, which was prevalent on the left side, was reported (La Marca et al. 2020). One import point was to know the transmission of SARS-CoV-2 through the semen (Patel et al. 2021). In a systematic review, it was emphasized that while SARS-CoV-2 might induce male infertility, there we no epidemiological evidence to confirm the sexual transmission of this virus (Tur-Kaspa et al. 2021) The orchitis and testicular damages due to infection by the CoVs family have been reported in humans (e.g., SARS-Co) (Xu et al. 2006) and animals (e.g., feline CoV) (Sigurðardóttir et al. 2001; Stranieri et al. 2020). While the various pathological characteristic with testicular damage and germ cell destruction was clearly observed in these cases (Xu et al. 2006), the presence of virus in the testis and direct infection of tissue is still the subject of debate due to conflicting findings (Ding et al. 2004; Gu et al. 2005; Xu et al. 2006).

It seems that SARS-CoV-2 may be transmitted by semen through the asymptomatic or mild patients even during the incubation period (Cardona Maya et al. 2020). The sexual transmission of the Zika virus and Ebola virus has been confirmed in the symptomatically infected patients and survivors of the disease (Feldmann 2018). The direct invasion of host cells via SARS-CoV-2 is under doubt (Ma et al. 2020; Song et al. 2020). Besides, orchitis and subsequent infertility in these patients should be considered as an important complication of disease.

Additionally, even researches on the presence of virus in the semen were unsuccessful, there are some evidences show the febrile episode due to the viral infection can affect the quality of sperm (Wiwanitkit 2010). This may result in reduced fertility due to lower sperm count and motility within 72-90 days following COVID19 (Segars et al. 2020). Also, the impairment of semen quality can be temporary 
when the fever is managed through therapeutic options, as it was reported in a case report following a recent acute fever of $38-39{ }^{\circ} \mathrm{C}$ due to a throat infection (Andrade-Rocha 2013). In another study, fever $\geq 39^{\circ} \mathrm{C}$ for duration of $\geq 3$ days led to temporary infertility with severely impaired semen quality and even azoospermia in five patients, which recovered in 4-6 months (Jung et al. 2001).

\section{SARS-CoV-2 effects on the male reproductive system: pathologic alterations and underlying mechanisms}

Microscopical evaluations of testis samples showed that the spermatogenesis process was not affected during the acute phase of the COVID-19. However, significant seminiferous tubular damage, swelling Sertoli cells, decreased Leydig cells, interstitial edema, and mild inflammation (predominant $\mathrm{T}$ lymphocytes) were observed. The authors proved that although spermatogenesis was normal at the time of analysis, functional changes in Sertoli and Leydig cells may lead to future testicular damage (Yang et al. 2020a). The results of another molecular and morphological evaluation of autopsy from six men with COVID-19 demonstrated the severe spermatogenesis damages in these patients compared to controls. In addition to the detection of viral RNA and particles, evaluation of TMPRSS2 and ACE2 was confirmed. Also, infiltration of different leukocytes (e.g., CD68 macrophages, CD3 T cells, CD20 B cells, CD38 plasma cells, and HLA-DR myeloid cells) was observed in histopathological evaluations (Ma et al. 2020). Recently, it was demonstrated that the serum luteinizing hormone (LH) was enhanced. In contrast, the ratio of testosterone/LH and ratio of follicle-stimulating hormone (FSH)/LH were dramatically reduced in 81 male cases with moderate-to-severe COVID19. No difference was observed in serum testosterone levels of COVID-19 patients and control groups (Ma et al. 2020). Although dysregulation of sex hormones was proven in this study, it is essential to repeat these measurements 3-6 months after recovery. In a cohort study on 221 consecutive male patients with COVID-19, reduced levels of testosterone were observed correlated with the severity of disease (Çayan et al. 2020). In a case report, the semen analysis of a COVID-19 patient 135 days after recovery showed improved sperm count and motility, but the morphological features remained poor with damaged DNA. During assisted reproductive technology, the lower quality of embryo was detected (Mannur et al. 2021). The underlying mechanisms of SARS-COV-2 in the involvement of the male genital tract are not clear. We discussed the potential mechanisms of SARS-CoV-2 in two direct and indirect pathways. Also, these mechanisms were summarized in Fig. 1.

\section{Direct mechanisms}

As described, SARS-CoV-2 uses the ACE2 receptor to infect host cells. Therefore, the presence of ACE2 on the cell surface increases the risk of local infection in the target organ (Mokhtari et al. 2020). The existence of ACE2 on different testicular cells such as spermatogonia, Leydig cells, and Sertoli cells has been confirmed (Douglas et al. 2004; Hamming et al. 2004; Wang and Xu 2020). Based on immunohistochemistry, the primary localization of ACE2 in Leydig cells of rat testis and Leydig cells, Sertoli cells, and glandular cells of seminal vesicles of the human testis has been confirmed (Douglas et al. 2004; Hikmet et al. 2020). The analysis of online databases revealed the expression of ACE2 in seminiferous duct cells and Leydig cells of human testis (Fan et al. 2020). The expression of ACE2 in Leydig cells in rodents and Leydig and Sertoli cells in humans has been reported to play a critical role in regulating testicular cells, particularly Leydig cell function, possibly controlling steroidogenesis and some other functions (Douglas et al. 2004). On the other hand, the existence of the angiotensin II (Ang II) receptor on the Leydig cell has been proven. Ang II inhibits the production of both basal and LH-stimulated testosterone synthesis by Leydig cells (Khanum and Dufau 1988). Also, bioinformatics analysis has shown the high mRNA and protein expression levels of ACE2 in the testis and spermatids (Zhang et al. 2020b). Therefore, the presence of ACE2 in testis may increase the risk of orchitis among the COVID-19 patients. There are limited studies to confirm the direct invasion of testicular cells via SARS-CoV-2. In a study, the absence of SARS-CoV-2 in semen and testes of 12 patients at both was confirmed in both acute and recovery phases (Song et al. 2020). In addition, there was no evidence to show the presence of SARS-CoV-2 in the semen of these patients (Pan et al. 2020). The postmortem RT-PCR evaluation of samples from the COVID-19 patient showed that viral RNA was not detected in testicular tissue (Song et al. 2020). In RT-PCR and electron microscopy, the RNA of SARS-CoV-2 was not detected in the reticular samples of COVID-19 patients (Yang et al. 2020a). However, the viral RNA, viral particles, and S- protein of the SARS-CoV-2 were detected in autopsy from six testes of COVID-19 patients (Ma et al. 2020). Recently, evidence from a survey on postmortem testis biopsies has confirmed that SARS-CoV-2 can directly invade the testis and germ cells. The presence of SARS-CoV-2 spike protein and viral nucleic acid in the testicular samples from COVID19 patients represent the potential impact of the COVID-19 on spermatogenesis. (Ma et al. 2021). While the results of these studies are considerable, their sample size involved a small population. Therefore, new investigations should be conducted on larger samples to detect the virus in the semen of COVID-19 patients. 


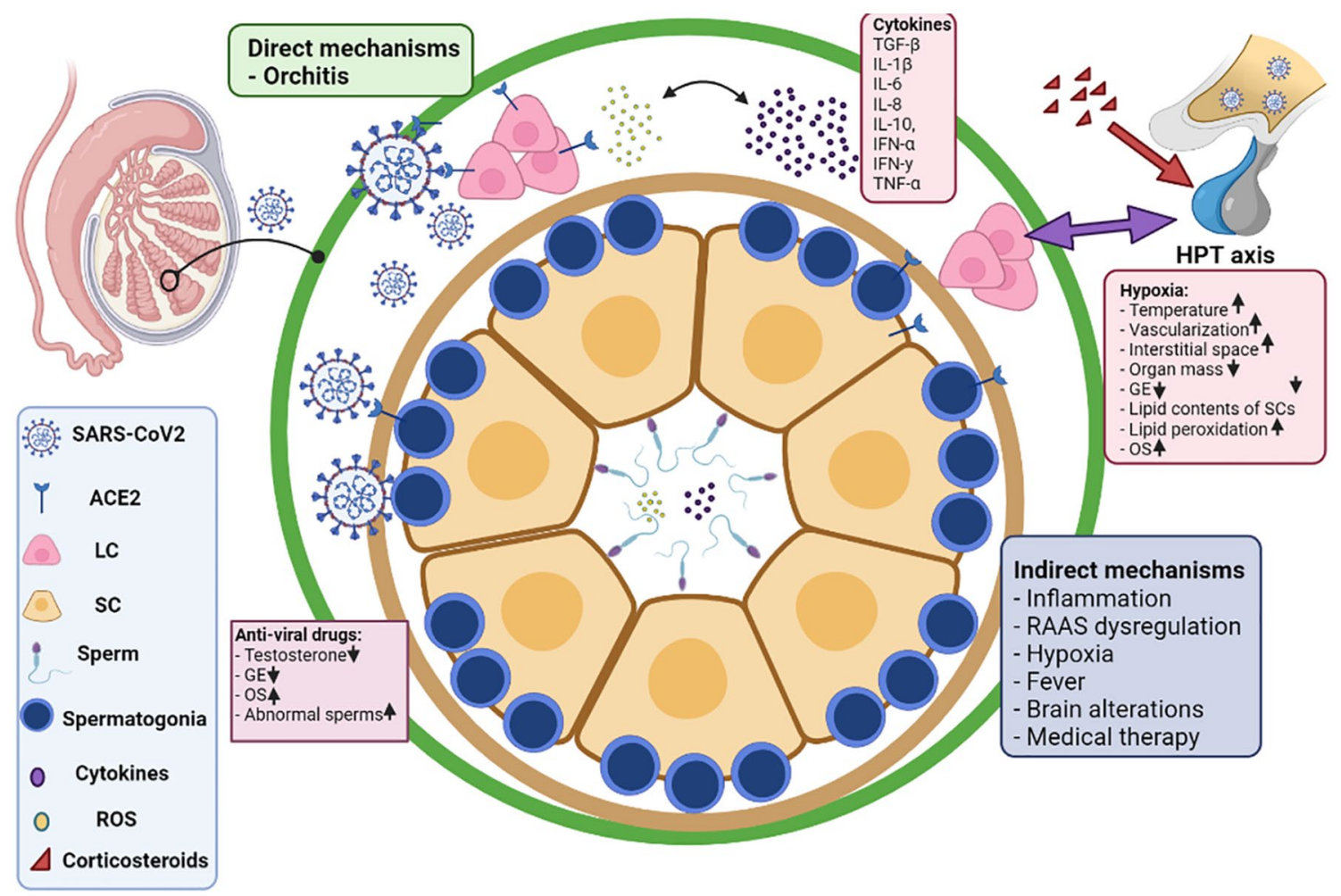

Fig. 1 Possible mechanism of SARS-COV-2 in induction of male infertility. SARS-COV-2 can affect male infertility by direct and indirect mechanisms. Directly, this virus invades cells of testicular tissue via binding ACE2 receptor. Indirectly, hyperinflammation (increased levels of cytokines), RAAS dysregulation, hypoxia, fever, brain alterations, and medical therapy can lead to dysregulation of testosterone,

\section{Indirect mechanisms}

\section{Inflammation}

Cytokine storm and hyperinflammation syndrome due to overexpression of cytokines and chemokines have been observed in COVID-19 patients (Tisoncik et al. 2012). Likewise, the cytokine storm might have a critical role in the pathogenesis of COVID-19 (Lin et al. 2018). The direct attack of the lung epithelial cells, macrophages, and dendritic cells by SARS-CoV-2 leads to the systemic cytokine storm, inducing microcirculation dysfunctions in other organs and results in viral sepsis (Li et al. 2020b). This phenomenon is responsible for frequent complications such as ARDS and respiratory failure due to edema in lung tissue and dysfunction in air exchange, hepatic and renal insufficiency in the severe cases of COVID-19, which increase the risk of death in infected patients (Channappanavar and Perlman 2017; Leng et al. 2020; Liu et al. 2020). The severity of disease COVID-19 patients correlated with systemic levels of several proinflammatory mediators such as interleukins (e.g., IL-1, IL-2, IL-7, and IL-6), tumor necrosis several pathological features, and the production of impaired sperms. $I L$ interleukin, $R A A S$ angiotensin-aldosterone system, $A C E$ angiotensin-converting enzyme, $T G F$ transforming growth factor, $T N F$ tumor necrosis factor, $I F N$ interferon, $G E$ germinal epithelium, $L C$ Leydig cells, $S C$ Sertoli cell, $O S$ oxidative stress, $R O S$ reactive oxygen species (Created with BioRender.com)

factor- $\alpha$ (TNF- $\alpha$ ), interferon- $\gamma$, inducible protein 10 (IP-10), monocyte chemoattractant protein-1 (MCP-1), granulocytecolony stimulating factor (GCSF), and macrophage inflammatory protein-1 $\alpha$ (MIP-1 $\alpha$ ) (Ruan et al. 2020; Wrapp et al. 2020). High levels of IP-10, GCSF, MCP-1, MIP-1 $\alpha$, and TNF- $\alpha$ have been demonstrated in patients requiring ICU admission (Chen et al. 2020; Huang et al. 2020). IL-6 is the most important factor among these mediators, as its role in the progress of inflammation in viral disease (Hou et al. 2014). Inflammasomes complex, which activates IL-1 $\beta$ by stimulation of caspase-1 (Bazrafkan et al. 2018), has been involved in viral infections (Farag et al. 2020). Cytokines play a critical role in the pathogenesis of infertility in male subjects (Loveland et al. 2017). High levels of cytokines in the reproductive tract (testis and epididymis) are inevitably related to oxidative stress, leading to sperm DNA damages and apoptosis (Azenabor et al. 2015). Deviations of cytokine microenvironment within the testicular tissue may induce tumorigenic adverse impacts, causing testicular cancer as a long-term outcome of inflammation (Loveland et al. 2017). On the other hand, dysregulated levels of inflammatory mediators (including Transforming growth 
factor- $\beta$, IL-1 $\beta$, IL-6, IL- 8 , IL-10, IFN- $\alpha$, IFN-y, and TNF$\alpha$ ), oxidative products (including ROS, caspase-3, caspase-8, and caspase-9), and oxidative enzymes (including superoxide dismutase) were reported in COCID-19 group (Maleki and Tartibian 2021). By the way, it has been stated that it takes 3-4 months to return sperm parameters to basal state (Bendayan and Boitrelle 2021). Taken together, controlling cytokine storm in patients with COVID-19 can prevent the organ dysfunction, particularly in the testis.

\section{The RAAS}

The RAAS activation is vital in the regulation of blood pressure, vascular tone, and hemostasis. Renin activation in the kidney in response to some stimuli (such as reduced blood pressure) converts angiotensinogen to Ang (I) ACE2 contributes to the conversation of Ang I to Ang II in the lung (Paul et al. 2006). Also, ACE2 can directly convert Ang I to Ang 1-9 (Ocaranza and Jalil 2012). Ang II applies its action through interacting with Ang II type 1 and 2 receptors (AT1R and AT2R) (Paul et al. 2006). ACE2 is another component of RAAS that cleaves Ang II to generate Ang 1-7. Ang 1-7 exerts its action through its receptor, MasR (Liao and Wu 2020). Recently, another fragment of Ang II Ang 3-8 with acting on its receptor, insulin-regulated aminopeptidase (IRAP or AT4R), was discovered (George et al. 2010). Regulation of blood pressure is performed via the pressor (ACE/Ang II/AT1R) and the depressor (ACE 2/Ang 1-7/MasR) arms of the RAAS. A growing body of evidence has confirmed a widespread local tissue RAAS. Although different RAAS family members are able to regulate testicular functions, the exact role of this system in the fertility is not cleared yet (Mentz et al. 2013). While ACE2 has been shown to affect the Leydig cells' function as a regulatory factor of the enzyme in steroidogenesis (Leal et al. 2009), the ACE2 knockout mice have been reported to be fertile without any gross structural abnormalities (Gurley et al. 2006). The presence of RAAS components (e.g., ACE) on several cell types of testis confirms that these components play a critical role in the regulation of steroidogenesis, testosterone secretion, spermatogenesis, epididymal contractility, and sperm function in the testis and epididymis (Reis et al. 2010; Younis et al. 2020). As mentioned before, ACE2 is highly expressed in both testicular germ and somatic cells (Shen et al. 2020; Younis et al. 2020). In addition, other RAAS peptides and related receptors such as Ang 1-7 have been detected in Sertoli cells and Leydig cells (Younis et al. 2020). Men with normal spermatogenesis show the high activity of ACE 2/Ang 1-7/MasR axis. Conversely, lower expression of MasR and ACE2 were identified in patients with abnormal spermatogenesis (Reis et al. 2010; Younis et al. 2020). It has been shown that Acel $^{-/-}$male mice have are sterile (Kessler et al. 2000). Despite the sperm motility and fusing location of eggs generated in Ace 2 and Ace 3- deficient and both proved to be fertile, the male mice were slightly abnormal (Crackower et al. 2002; Inoue et al. 2010). It has been recorded that MasR- null mice exert reduced daily sperm count and impaired spermatogenesis through increased apoptosis during meiosis (Leal et al. 2009). The lower expression of ACE 2 on the cell surface after binding of the virus decreases the cleavage of Ang II to Ang 1-7, as well as Ang I to Ang 1-9 in the cell, leading to an increase amount of Ang (II) This accumulation can contribute to toxicity and inflammation in tissues with high expression of ACE2 (Fu et al. 2020; Naik 2020). Although the ACE2 role in the local vascular regulatory system and its relationship with Leydig cells, also direct and indirect regulator of microvascular flow characteristics has been proven (Widmark et al. 1986), this receptor has no hormonally control in the intact testis. There is no evidence to explain effects of the entire RAAS pathway within the testis (Douglas et al. 2004). Increased levels of serum LH and decreased testosterone/LH ratio are often clinical signs of primary hypogonadism (Hikmet et al. 2020), confirming Leydig cell dysfunction. Altered levels of sex hormones can explain how testicular impairment is induced by Leydig cell dysfunction due to the lower ACE2 activity and the Ang II/ AT1R pathway imbalance.

\section{Hypoxia}

The acute respiratory distress syndrome (ARDS) and impaired gas exchange lead to systemic hypoxia in COVID19 patients (Serebrovska et al. 2020). Since SARS-CoV-2 was not detected in the specimens, histopathological alterations in testicular tissue can be induced by hypoxia. The testicular dysfunction has been observed in conditions with the systemic oxygen deficit, such as mountaineers, obstructive pulmonary disease, pulmonary alveolar proteinosis, sleep apnea, sickle cell disease, and beta-thalassaemia (Bomhard and Gelbke 2013; Torres et al. 2014). Lower levels of testosterone was correlated with the severity of disease in men with ARDS (Heffernan et al. 2011). The hypoxic condition induces some testicular alterations, e.g., enhanced temperature, vascularization, and interstitial space, as well as reduced organ mass (Farias et al. 2005; Reyes et al. 2012). Histopathological studies have proven that exposure to chronic hypoxia induces some changes, including folding of the basement membrane, degeneration of germinal epithelium, detachment of germ cells, alterations in lipid contents of Sertoli cells, and elevated lipid peroxidation (Farias et al. 2005; Liao et al. 2010). The evidence shows that chronic hypoxia causes reversible injury (reduced sperm count and motility) on male fertility (Verratti et al. 2008). In an animal model of obstructive sleep apnea (OSA), it was shown that hypoxia was associated with increased oxidative 
stress (reduced expression of glutathione peroxidase 1 and superoxide dismutase-1) and decreased fertility (impaired progressive sperm motility) (Torres et al. 2014). Hypoxia triggers systemic and organ-related oxidative stress and affects organ function (Lavie 2009). Taken together, reduced oxygen content in COVID-19 patients can induce reversibly reduced fertility due to increased oxidative stress in testicular tissue.

\section{Fever}

Fever is a primary manifestation of COVID-19 observed in $80 \%$ of patients ( $\mathrm{Li}$ et al. 2020c). High and sustained elevation in body temperature has been reported to impact spermatogenesis and leads to reduce the quality of sperm in viral infections (Wiwanitkit 2010). High fever can affect chromatin structure infertility in humans and animals (Evenson et al. 2000; Sharma and Polasa 1978). Hyperthermia increases the intratesticular temperature and causes vascular disturbances, which itself triggers the inflammation in testicular tissue. It has suppressive effects on steroidogenesis and spermatogenesis (Fijak et al. 2018).

\section{Brain alterations}

Altered levels of gonadotropins and testosterone in male COVID-19 subjects might be due to the dysregulation of hypothalamic-pituitary-testicular (HPT) axis (Tian and Zhou 2021). Nevertheless, SARS-CoV-2-mediated dysregulation of the HPT axis remains unclear (Pal and Banerjee 2020). While there is an association between impaired HPT axis and Leydig cell dysfunction, increasing evidence shows that hypothalamus abnormalities can be responsible for the dysregulated secretion of testes-derived sex steroid hormones (Selvaraj et al. 2021). Hypothalamic lesions in patients with COVID-19 have been recorded (Pascual-Goñi et al. 2020), increasing the risk of HPT axis dysfunction. In addition, high expression of ACE2 in the hypothalamus makes this region a hub for SARS-CoV-2 infection (Nampoothiri et al. 2020). Moreover, dysregulation of the HPT axis can be a psychological impact of COVID-19 pandemic. Fear and stress in patients with COVID-19 can induce several mental problems, including anxiety, depression, post-traumatic stress disorder, and sleep disturbances (Koçak et al. 2021). Recently, it was reported that survivors of COVID-19 showed anxiety disorder (19.15\%) and psychotic disorders (2.77\%) 6 months after recovery (Taquet et al. 2021). Stressors have been identified as potential risk factors of male infertility, as they negatively affect semen parameters (Taquet et al. 2021). The psychological stress is regulated by the paraventricular nucleus (PVN) of the hypothalamus. PVN secrets corticotropin releasing hormone $(\mathrm{CRH})$ and controls hypothalamic-pituitary-adrenal
(HPA) axis (Nargund 2015). CRH stimulates the secretion of adrenocorticotropic hormone (ACTH) secretion from the anterior pituitary gland (Kalantaridou et al. 2010). ACTH directly affects the secretion of glucocorticoids from the adrenal cortex, the final mediator of the HPA axis (Habib et al. 2001). Increased activity HPA axis due to stressors has a direct inhibitory effect on gonadotropin-releasing hormone (GnRH) secretion mediated through glucocorticoids, resulting in sex hormone reductions and sperm abnormalities (Kirby et al. 2009). Therefore, the mental and pathological impacts of COVID-19 on hypothalamus should be highly considered in patients or recovered cases with abnormal gonadotropin hormone levels.

\section{Medical therapy}

Immunomodulatory therapies may provoke potential longterm effects on male fertility and are a matter of concern. It has been shown that chronic use and high dose of corticosteroids can inhibit the HPT axis (low testosterone levels) and induce erectile dysfunction. Chronic administration of non-steroidal anti-inflammatory drugs (NSAIDs) can affect sperm quality by reducing sperm motility, vitality, count, and morphology. These effects are reversible and dosedependent (Mendonça et al. 2000). Moreover, the treatment of COVID-19 patients with anti-viral drugs (e.g., ribavirin) reduces testosterone levels, induces oxidative stress, impairs seminiferous epithelium, and causes the formation of abnormal sperms (Almasry et al. 2017; Narayana et al. 2005).

\section{Conclusions}

Based on current knowledge, the male reproductive system involvement in critically ill patients needs to be considered by the health care system. Because of limited evidence on the testis infection by SARS-COV-2 in asymptomatic patients or during incubation, people need to be protected in their sexual contact. Management strategies and providing sperm donation programs are necessary during the COVID19 disease course. Also, some protective approaches, such as using antioxidants, can be prescribed to reduce the oxidative stress-induced injuries in testicular tissue in patients with fever and multiorgan dysfunction. Further studies are required to manage the reproductive health parameters and HPT axis abnormalities related to secondary mental and pathological complications in the positive individuals during and after the recovery from COVID- 19.

Author contributions DA conceived of the presented idea. AA, and DA equally participated in drafting the article. AA and DA participated in 
revising it critically for important intellectual content. AA gave final approval of the version to be submitted and any revised version.

Funding No funding to declare.

\section{Declarations}

Conflict of interest The authors declare that they have no conflict of interest.

\section{Research involving human participants and/or animals N/A.}

Informed consent N/A.

Consent to publish N/A.

\section{References}

Adhikari SP et al (2020) Epidemiology, causes, clinical manifestation and diagnosis, prevention and control of coronavirus disease (COVID-19) during the early outbreak period: a scoping review. Infect Dis Poverty 9:29. https://doi.org/10.1186/ s40249-020-00646- $\mathrm{x}$

Almasry SM, Hassan ZA, Elsaed WM, Elbastawisy YM (2017) Structural evaluation of the peritubular sheath of rat's testes after administration of ribavirin: a possible impact on the testicular function. Int J Immunopathol Pharmacol 30:282-296. https:// doi.org/10.1177/0394632017726261

Andersen KG, Rambaut A, Lipkin WI, Holmes EC, Garry RF (2020) The proximal origin of SARS-CoV-2. Nat Med 26:450-452

Andrade-Rocha FT (2013) Temporary impairment of semen quality following recent acute fever. Ann Clin Lab Sci 43:94-97

Azenabor A, Ekun AO, Akinloye O (2015) Impact of inflammation on male reproductive tract. J Reprod Infertil 16:123-129

Bazrafkan M et al (2018) Lipid peroxidation and its role in the expression of NLRP1a and NLRP3 genes in testicular tissue of male rats: a model of spinal cord injury. Iran Biomed J 22:151

Bendayan M, Boitrelle F (2021) What could cause the long-term effects of COVID-19 on sperm parameters and male fertility? QJM. https://doi.org/10.1093/qjmed/hcab028

Bomhard EM, Gelbke HP (2013) Hypoxaemia affects male reproduction: a case study of how to differentiate between primary and secondary hypoxic testicular toxicity due to chemical exposure. Arch Toxicol 87:1201-1218. https://doi.org/10.1007/ s00204-013-1024-6

Cabeça TK, Granato C, Bellei N (2013) Epidemiological and clinical features of human coronavirus infections among different subsets of patients. Influ Other Respir Viruses 7:1040-1047. https://doi. org/10.1111/irv.12101

Cardona Maya WD, Du Plessis SS, Velilla PA (2020) SARS-CoV-2 and the testis: similarity with other viruses and routes of infection. Reprod Biomed Online. https://doi.org/10.1016/j.rbmo. 2020.04.009

Çayan S, Uğuz M, Saylam B, Akbay E (2020) Effect of serum total testosterone and its relationship with other laboratory parameters on the prognosis of coronavirus disease 2019 (COVID-19) in SARS-CoV-2 infected male patients: a cohort study. Aging Male 23:1493-1503. https://doi.org/10.1080/13685538.2020.1807930

Channappanavar R, Perlman S (2017) Pathogenic human coronavirus infections: causes and consequences of cytokine storm and immunopathology. Semin Immunopathol 39:529-539. https:// doi.org/10.1007/s00281-017-0629-x
Chen $\mathrm{N}$ et al (2020) Epidemiological and clinical characteristics of 99 cases of 2019 novel coronavirus pneumonia in Wuhan, China: a descriptive study. Lancet 395:507-513. https://doi. org/10.1016/s0140-6736(20)30211-7

Crackower MA et al (2002) Angiotensin-converting enzyme 2 is an essential regulator of heart function. Nature 417:822-828. https://doi.org/10.1038/nature00786

Cui P et al (2020) Clinical features and sexual transmission potential of SARS-CoV-2 infected female patients: a descriptive study in Wuhan, China. medRxiv

Dawood FS et al (2009) Emergence of a novel swine-origin influenza A (H1N1) virus in humans. N Engl J Med 360:2605-2615. https://doi.org/10.1056/NEJMoa0903810

Ding Y et al (2004) Organ distribution of severe acute respiratory syndrome (SARS) associated coronavirus (SARS-CoV) in SARS patients: implications for pathogenesis and virus transmission pathways. J Pathol 203:622-630. https://doi.org/10. 1002/path. 1560

Douglas GC, O’Bryan MK, Hedger MP, Lee DK, Yarski MA, Smith AI, Lew RA (2004) The novel angiotensin-converting enzyme (ACE) homolog, ACE2, is selectively expressed by adult Leydig cells of the testis. Endocrinology 145:4703-4711. https:// doi.org/10.1210/en.2004-0443

El Zowalaty ME, Järhult JD (2020) From SARS to COVID-19: a previously unknown SARS-related coronavirus (SARS-CoV-2) of pandemic potential infecting humans-Call for a One Health approach. One Health 9:100124. https://doi.org/10.1016/j.onehlt.2020.100124

Evenson DP, Jost LK, Corzett M, Balhorn R (2000) Characteristics of human sperm chromatin structure following an episode of influenza and high fever: a case study. J Androl 21:739-746

Fan C, Li K, Ding Y, Lu WL, Wang J (2020) ACE2 expression in kidney and testis may cause kidney and testis damage after 2019-nCoV infection. MedRxiv

Farag NS, Breitinger U, Breitinger HG, El Azizi MA (2020) Viroporins and inflammasomes: a key to understand virus-induced inflammation. Int J Biochem Cell Biol 122:105738. https://doi. org/10.1016/j.biocel.2020.105738

Farias JG, Bustos-Obregón E, Orellana R, Bucarey J, Quiroz E, Reyes J (2005) Effects of chronic hypobaric hypoxia on testis histology and round spermatid oxidative metabolism. Andrologia 37:47-52

Feldmann H (2018) Virus in semen and the risk of sexual transmission. N Engl J Med 378:1440-1441. https://doi.org/10.1056/NEJMe 1803212

Fijak M et al (2018) Infectious, inflammatory and 'autoimmune' male factor infertility: how do rodent models inform clinical practice? Hum Reprod Update 24:416-441

$\mathrm{Fu} \mathrm{J}$ et al (2020) Expressions and significances of the angiotensinconverting enzyme 2 gene, the receptor of SARS-CoV-2 for COVID-19. Mol Biol Rep 47:4383-4392

George AJ, Thomas WG, Hannan RD (2010) The renin-angiotensin system and cancer: old dog, new tricks. Nat Rev Cancer 10:745-759

$\mathrm{Gu} \mathrm{J}$ et al (2005) Multiple organ infection and the pathogenesis of SARS. J Exp Med 202:415-424. https://doi.org/10.1084/jem. 20050828

Guo YR et al (2020) The origin, transmission and clinical therapies on coronavirus disease 2019 (COVID-19) outbreak-an update on the status. Mil Med Res 7:11. https://doi.org/10.1186/ s40779-020-00240-0

Gurley SB et al (2006) Altered blood pressure responses and normal cardiac phenotype in ACE2-null mice. J Clin Investig 116:22182225. https://doi.org/10.1172/jci16980

Habib KE, Gold PW, Chrousos GP (2001) Neuroendocrinology of stress. Endocrinol Metab Clin 30:695-728 
Hamming I, Timens W, Bulthuis ML, Lely AT, Navis G, van Goor $\mathrm{H}$ (2004) Tissue distribution of ACE2 protein, the functional receptor for SARS coronavirus. A first step in understanding SARS pathogenesis. J Pathol 203:631-637. https://doi.org/10. 1002/path. 1570

He L et al (2006) Expression of elevated levels of pro-inflammatory cytokines in SARS-CoV-infected ACE2+ cells in SARS patients: relation to the acute lung injury and pathogenesis of SARS. J Pathol 210:288-297. https://doi.org/10.1002/path.2067

Heffernan DS, Dossett LA, Lightfoot MA, Fremont RD, Ware LB, Sawyer RG, May AK (2011) Gender and acute respiratory distress syndrome in critically injured adults: a prospective study. J Trauma 71:878-883. https://doi.org/10.1097/TA.0b013e3182 2c0d31 (discussion 883-875)

Hikmet F, Méar L, Edvinsson Å, Micke P, Uhlén M, Lindskog C (2020) The protein expression profile of ACE2 in human tissues. Mol Syst Biol 16:e9610. https://doi.org/10.15252/msb.20209610

Hoffmann $M$ et al (2020) SARS-CoV-2 cell entry depends on ACE2 and TMPRSS 2 and is blocked by a clinically proven protease inhibitor. Cell 181(2):271-280.e8. https://doi.org/10.1016/j.cell. 2020.02.052

Hou W, Jin YH, Kang HS, Kim BS (2014) Interleukin-6 (IL-6) and IL-17 synergistically promote viral persistence by inhibiting cellular apoptosis and cytotoxic T cell function. J Virol 88:84798489. https://doi.org/10.1128/jvi.00724-14

Huang C et al (2020) Clinical features of patients infected with 2019 novel coronavirus in Wuhan, China. Lancet 395:497-506

Inoue N, Kasahara T, Ikawa M, Okabe M (2010) Identification and disruption of sperm-specific angiotensin converting enzyme-3 (ACE3) in mouse. PLoS One 5:e10301. https://doi.org/10.1371/ journal.pone.0010301

Jin J-M et al (2020) Gender differences in patients with COVID-19: focus on severity and mortality. Front Public Health 8:152

Jung A, Schuppe HC, Schill WB (2001) Fever as etiology of temporary infertility in the man. Hautarzt 52:1090-1093. https://doi.org/10. 1007/s001050170018

Kalantaridou S, Zoumakis E, Makrigiannakis A, Lavasidis L, Vrekoussis T, Chrousos G (2010) Corticotropin-releasing hormone, stress and human reproduction: an update. J Reprod Immunol 85:33-39

Kang S et al (2020) Recent progress in understanding 2019 novel coronavirus (SARS-CoV-2) associated with human respiratory disease: detection, mechanisms and treatment. Int J Antimicrob Agents. https://doi.org/10.1016/j.ijantimicag.2020.105950

Kessler SP, Rowe TM, Gomos JB, Kessler PM, Sen GC (2000) Physiological non-equivalence of the two isoforms of angiotensinconverting enzyme. J Biol Chem 275:26259-26264. https://doi. org/10.1074/jbc.M004006200

Khanum A, Dufau ML (1988) Angiotensin II receptors and inhibitory actions in Leydig cells. J Biol Chem 263:5070-5074

Kirby ED, Geraghty AC, Ubuka T, Bentley GE, Kaufer D (2009) Stress increases putative gonadotropin inhibitory hormone and decreases luteinizing hormone in male rats. Proc Natl Acad Sci USA 106:11324-11329

Koçak O, Koçak ÖE, Younis MZ (2021) The psychological consequences of COVID-19 fear and the moderator effects of individuals' underlying illness and witnessing infected friends and family. Int J Environ Res Public Health 18:1836

La Marca A, Busani S, Donno V, Guaraldi G, Ligabue G, Girardis M (2020) Testicular pain as an unusual presentation of COVID-19: a brief review of SARS-CoV-2 and the testis. Reprod Biomed Online. https://doi.org/10.1016/j.rbmo.2020.07.017

Lavie L (2009) Oxidative stress-a unifying paradigm in obstructive sleep apnea and comorbidities. Prog Cardiovasc Dis 51:303-312. https://doi.org/10.1016/j.pcad.2008.08.003
Leal MC et al (2009) The role of angiotensin-(1-7) receptor Mas in spermatogenesis in mice and rats. J Anat 214:736-743. https:// doi.org/10.1111/j.1469-7580.2009.01058.x

Leng Z et al (2020) Transplantation of ACE2-mesenchymal stem cells improves the outcome of patients with COVID-19 pneumonia. Aging Dis 11:216-228

Li G et al (2020a) Coronavirus infections and immune responses. J Med Virol 92:424-432. https://doi.org/10.1002/jmv.25685

Li H et al (2020b) SARS-CoV-2 and viral sepsis: observations and hypotheses. Lancet. https://doi.org/10.1016/s0140-6736(20) 30920-x

Li L et al (2020c) COVID-19 patients' clinical characteristics, discharge rate, and fatality rate of meta-analysis. J Med Virol 92:577-583

Liao W, Wu J (2020) The ACE2/Ang (1-7)/MasR axis as an emerging target for antihypertensive peptides. Crit Rev Food Sci Nutr 18:1-15

Liao W, Cai M, Chen J, Huang J, Liu F, Jiang C, Gao Y (2010) Hypobaric hypoxia causes deleterious effects on spermatogenesis in rats. Reproduction 139:1031-1038

Lin G-L, McGinley JP, Drysdale SB, Pollard AJ (2018) Epidemiology and immune pathogenesis of viral sepsis. Front Immunol 9:2147-2147. https://doi.org/10.3389/fimmu.2018.02147

Liu Z et al (2020) Composition and divergence of coronavirus spike proteins and host ACE2 receptors predict potential intermediate hosts of SARS-CoV-2. J Med Virol 92(6):595-601. https:// doi.org/10.1002/jmv.25726

Loveland KL et al (2017) Cytokines in male fertility and reproductive pathologies: immunoregulation and beyond. Front Endocrinol (Lausanne) 8:307. https://doi.org/10.3389/fendo.2017. 00307

Lu R et al (2020) Genomic characterisation and epidemiology of 2019 novel coronavirus: implications for virus origins and receptor binding. Lancet 395:565-574. https://doi.org/10.1016/s01406736(20)30251-8

Ma L et al (2020) Effect of SARS-CoV-2 infection upon male gonadal function: a single center-based study. Preprint from medRxiv. https://doi.org/10.1101/2020.03.21.20037267

Ma X et al (2021) Pathological and molecular examinations of postmortem testis biopsies reveal SARS-CoV-2 infection in the testis and spermatogenesis damage in COVID-19 patients. Cell Mol Immunol 18:487-489

Maleki BH, Tartibian B (2021) COVID-19 and male reproductive function: a prospective, longitudinal cohort study. Reproduction $161: 319-331$

Mannur S, Jabeen T, Khader MA, Rao LSS (2021) Post-COVID-19-associated decline in long-term male fertility and embryo quality during assisted reproductive technology. QJM 28:hcab019

Matoba Y et al (2015) Detection of the human coronavirus 229E, HKU1, NL63, and OC43 between 2010 and 2013 in Yamagata, Japan. Jpn J Infect Dis 68:138-141. https://doi.org/10.7883/ yoken.JJID.2014.266

McMichael TM (2020) COVID-19 in a long-term care facility-King County, Washington, February 27-March 9, 2020. MMWR Morb Mortal Wkly Rep 69(12):339-342

Mentz RJ et al (2013) The past, present and future of renin-angiotensin aldosterone system inhibition. Int J Cardiol 167(5):1677-1687. https://doi.org/10.1016/j.ijcard.2012.10.007

Mendonça LL, Khamashta MA, Nelson-Piercy C, Hunt BJ, Hughes GR (2000) Non-steroidal anti-inflammatory drugs as a possible cause for reversible infertility. Rheumatology 39:880-882. https://doi. org/10.1093/rheumatology/39.8.880

Mohamed Khosroshahi L, Rokni M, Mokhtari T, Noorbakhsh F (2021) Immunology, immunopathogenesis and immunotherapeutics of COVID-19; an overview. Int Immunopharmacol 93:107364. https://doi.org/10.1016/j.intimp.2020.107364 
Mokhtari T, Hassani F, Ghaffari N, Ebrahimi B, Yarahmadi A, Hassanzadeh G (2020) COVID-19 and multiorgan failure: a narrative review on potential mechanisms. J Mol Histol 51:613-628. https://doi.org/10.1007/s10735-020-09915-3

Naicker S, Yang CW, Hwang SJ, Liu BC, Chen JH, Jha V (2020) The Novel Coronavirus 2019 epidemic and kidneys. Kidney Int 97(5):824-828. https://doi.org/10.1016/j.kint.2020.03.001

Naik GO (2020) COVID-19 and the renin-angiotensin-aldosterone system. Clin Infect Dis 72(6):1105-1107. https://doi.org/10. 1093/cid/ciaa818

Nampoothiri S et al (2020) The hypothalamus as a hub for SARSCoV-2 brain infection and pathogenesis. bioRxiv Link: https:// www.biorxiv.org/content/. https://doi.org/10.1101/2020.06.08. $139329 v 2$

Narayana K, D’Souza UJ, Narayan P, Kumar G (2005) The antiviral drug ribavirin reversibly affects the reproductive parameters in the male Wistar rat. Folia Morphol (Warsz) 64:65-71

Nargund VH (2015) Effects of psychological stress on male fertility. Nat Rev Urol 12:373-382. https://doi.org/10.1038/nrurol.2015. 112

Ocaranza MP, Jalil JE (2012) Protective role of the ACE2/Ang-(1-9) axis in cardiovascular remodeling. Int J Hypertens 2012:594361594361. https://doi.org/10.1155/2012/594361

Pal R, Banerjee M (2020) COVID-19 and the endocrine system: exploring the unexplored. J Endocrinol Investig 43:1027-1031

Pan F et al (2020) No evidence of severe acute respiratory syndromecoronavirus 2 in semen of males recovering from coronavirus disease 2019. Fertil Steril 113:1135-1139. https://doi.org/10. 1016/j.fertnstert.2020.04.024

Pascual-Goñi E et al (2020) COVID-19-associated ophthalmoparesis and hypothalamic involvement. Neurol Neuroimmunol Neuroinflamm 7(5):e823

Patel DP, Punjani N, Guo J, Alukal JP, Li PS, Hotaling JM (2021) The impact of SARS-CoV-2 and COVID-19 on male reproduction and men's health. Fertil Steril 115:813-823. https://doi.org/10. 1016/j.fertnstert.2020.12.033

Paul M, Poyan Mehr A, Kreutz R (2006) Physiology of local reninangiotensin systems. Physiol Rev 86:747-803

Prompetchara E, Ketloy C, Palaga T (2020) Immune responses in COVID-19 and potential vaccines: lessons learned from SARS and MERS epidemic. Asian Pac J Allergy Immunol 38:1-9

Reis AB, Araújo FC, Pereira VM, Dos Reis AM, Santos RA, Reis FM (2010) Angiotensin (1-7) and its receptor Mas are expressed in the human testis: implications for male infertility. J Mol Histol 41:75-80. https://doi.org/10.1007/s10735-010-9264-8

Reyes JG, Farias JG, Henríquez-Olavarrieta S, Madrid E, Parraga M, Zepeda AB, Moreno RD (2012) The hypoxic testicle: physiology and pathophysiology. Oxid Med Cell Longev 2012:929285. https://doi.org/10.1155/2012/929285

Roca-Ho H, Riera M, Palau V, Pascual J, Soler MJ (2017) Characterization of ACE and ACE2 expression within different organs of the NOD mouse. Int J Mol Sci 18:563. https://doi.org/10.3390/ ijms 18030563

Ruan Q, Yang K, Wang W, Jiang L, Song J (2020) Clinical predictors of mortality due to COVID-19 based on an analysis of data of 150 patients from Wuhan, China. Intensive Care Med. https:// doi.org/10.1007/s00134-020-05991-x

Segars J et al (2020) Prior and Novel Coronaviruses, COVID-19, and human reproduction: what is known? Fertil Steril 113(6):1140 1149. https://doi.org/10.1016/j.fertnstert.2020.04.025

Selvaraj K, Ravichandran S, Krishnan S, Radhakrishnan RK, Manickam N, Kandasamy M (2021) Testicular atrophy and hypothalamic pathology in COVID-19: possibility of the incidence of male infertility and HPG axis abnormalities. Reprod Sci 7:1-8. https://doi.org/10.1007/s43032-020-00441-x
Serebrovska ZO, Chong EY, Serebrovska TV, Tumanovska LV, Xi L (2020) Hypoxia, HIF-1 $\alpha$, and COVID-19: from pathogenic factors to potential therapeutic targets. Acta Pharmacol Sin 41(12):1539-1546

Shanmugaraj B, Siriwattananon K, Wangkanont K, Phoolcharoen W (2020) Perspectives on monoclonal antibody therapy as potential therapeutic intervention for Coronavirus disease-19 (COVID-19). Asian Pac J Allergy Immunol 38(1):10-18

Sharma G, Polasa H (1978) Cytogenetic effects of influenza virus infection on male germ cells of mice. Hum Genet 45:179-187. https:// doi.org/10.1007/bf00286960

Shen Q, Xiao X, Aierken A, Yue W, Wu X, Liao M, Hua J (2020) The ACE2 expression in Sertoli cells and germ cells may cause male reproductive disorder after SARS-CoV-2 infection. J Cell Mol Med 24:9472-9477. https://doi.org/10.1111/jcmm.15541

Shenoy V, Qi Y, Katovich MJ, Raizada MK (2011) ACE2, a promising therapeutic target for pulmonary hypertension. Curr Opin Pharmacol 11:150-155

Shirato K et al (2014) Detection of Middle East respiratory syndrome coronavirus using reverse transcription loop-mediated isothermal amplification (RT-LAMP). Virol J 11:139. https://doi.org/ 10.1186/1743-422x-11-139

Sigurðardóttir Ó, Kolbjørnsen Ø, Lutz H (2001) Orchitis in a cat associated with coronavirus infection. J Comp Pathol 124:219-222

Song C et al (2020) Absence of 2019 novel coronavirus in semen and testes of COVID-19 patients. Biol Reprod 103:4-6. https://doi. org/10.1093/biolre/ioaa050

Stranieri A et al (2020) Preliminary investigation on feline coronavirus presence in the reproductive tract of the tom cat as a potential route of viral transmission. J Feline Med Surg 22:178-185

Taquet M, Geddes JR, Husain M, Luciano S, Harrison PJ (2021) 6-month neurological and psychiatric outcomes in 236379 survivors of COVID-19: a retrospective cohort study using electronic health records. Lancet Psychiatry 8(5):416-427

Tian Y, Zhou L-q (2021) Evaluating the impact of COVID-19 on male reproduction. Reproduction 161:R37-R44

Tisoncik JR, Korth MJ, Simmons CP, Farrar J, Martin TR, Katze MG (2012) Into the eye of the cytokine storm. Microbiol Mol Biol Rev 76:16-32. https://doi.org/10.1128/MMBR.05015-11

Torres M et al (2014) Male fertility is reduced by chronic intermittent hypoxia mimicking sleep apnea in mice. Sleep 37:1757-1765. https://doi.org/10.5665/sleep.4166

Tur-Kaspa I, Tur-Kaspa T, Hildebrand G, Cohen D (2021) COVID-19 may affect male fertility but is not sexually transmitted: a systematic review. F\&S Rev 2:140-149. https://doi.org/10.1016/j. xfnr.2021.01.002

Verratti V et al (2008) Evidence that chronic hypoxia causes reversible impairment on male fertility. Asian J Androl 10:602-606. https:// doi.org/10.1111/j.1745-7262.2008.00346.x

Wang Z, Xu X (2020) scRNA-seq profiling of human testes reveals the presence of the ACE2 receptor, a target for SARS-CoV-2 infection in spermatogonia, Leydig and Sertoli cells. Cells 9:920

Wang T, Du Z, Zhu F, Cao Z, An Y, Gao Y, Jiang B (2020) Comorbidities and multi-organ injuries in the treatment of COVID-19. Lancet 395:e52

Widmark A, Damber JE, Bergh A (1986) Relationship between human chorionic gonadotrophin-induced changes in testicular microcirculation and the formation of testicular interstitial fluid. $\mathbf{J}$ Endocrinol 109:419-425. https://doi.org/10.1677/joe.0.1090419

Wiwanitkit V (2010) Influenza, swine flu, sperm quality and infertility: a story. J Hum Reprod Sci 3:116-117. https://doi.org/10.4103/ 0974-1208.69339

Wrapp D et al (2020) Cryo-EM structure of the 2019-nCoV spike in the prefusion conformation. Science 367:1260-1263

$\mathrm{Xu} \mathrm{J}$ et al (2006) Orchitis: a complication of severe acute respiratory syndrome (SARS). Biol Reprod 74:410-416 
Yang M et al (2020a) Pathological findings in the testes of COVID19 patients: clinical implications. Eur Urol Focus 6:1124-1129. https://doi.org/10.1016/j.euf.2020.05.009

Yang Y et al (2020b) The deadly coronaviruses: the 2003 SARS pandemic and the 2020 novel coronavirus epidemic in China. J Autoimmun 109:102434

Younis JS, Abassi Z, Skorecki K (2020) Is there an impact of the COVID-19 pandemic on male fertility? The ACE2 connection. Am J Physiol Endocrinol Metab 318:E878-E880. https://doi.org/ 10.1152/ajpendo.00183.2020

Zhang H, Penninger JM, Li Y, Zhong N, Slutsky AS (2020a) Angiotensin-converting enzyme 2 (ACE2) as a SARS-CoV-2 receptor: molecular mechanisms and potential therapeutic target. Intensive Care Med 46(4):586-590. https://doi.org/10.1007/ s00134-020-05985-9

Zhang J et al (2020b) Bioinformatic analysis reveals that the reproductive system is potentially at risk from SARS-CoV-2. Ann Transl Med 9(8):678. https://doi.org/10.21037/atm-21-936
Zhou F et al (2020) Clinical course and risk factors for mortality of adult inpatients with COVID-19 in Wuhan, China: a retrospective cohort study. Lancet 395(10229):1054-1062. https://doi.org/10. 1016/S0140-6736(20)30566-3

Zou X, Chen K, Zou J, Han P, Hao J, Han Z (2020) Single-cell RNAseq data analysis on the receptor ACE2 expression reveals the potential risk of different human organs vulnerable to 2019nCoV infection. Front Med 14(2):185-192. https://doi.org/10. 1007/s11684-020-0754-0

Publisher's Note Springer Nature remains neutral with regard to jurisdictional claims in published maps and institutional affiliations. 